\title{
Skillful Disposition and Responsiveness in Mental Imagery
}

\author{
Christopher Joseph An \\ Philosophy Department \\ Ateneo de Manila University \\ cjan.phil@gmail.com
}

Received 2 July 2018; accepted 13 November 2018; published 11 December 2019

\begin{abstract}
This paper aims to explore and expand on Wittgenstein's remarks on the nature of mental imagery. Despite some rather cryptic passages and obvious objections, his notion of mental imagery as possessing a constitutive (and not merely added) element of expressive thought and conceptuality offers critical insights linking perceptual capacities with our shared practices. In particular I seek to further develop Wittgenstein's claim that perceptual impressions presuppose a "mastery of a technique." I argue that this sense of technique, understood as acquired conceptual capacities, can explain and capture the rich and varied spectrum of expressive visual content that can be accessed by human beings initiated and embedded in a variety of shared practices. Using Gilbert Ryle's account of dispositions, I cash out the notion of acquired conceptual capacities as spanning a wide latitude of responsive dispositions from mere "blind" visual habits to more normativelyguided, intelligent, and deliberately-trained visual "skills." Visual impressions construed as such are hardly perceptually (nor representationally) univocal and instead exhibit a dynamic and reflexive plurivocity manifested through one's initiation into shared practices and forms of life. This plurivocity makes possible a rich array of visual affordances that would otherwise not be accessible outside the context of a shared practice. This suggests that human beings possess a distinctive kind of expressive and responsive intelligence which picks out visual affordances determined not so much by a merely receptive perceptual faculty but by the subject's skillful, active, and responsive engagement with the world.
\end{abstract}

Keywords: Wittgenstein; mental imagery; conceptual capacities; visual affordances; acquired dispositions. 


\section{Introduction: Wittgenstein on Mental Imagery}

Ludwig Wittgenstein in his Philosophical Investigations (hereafter PI) targets a conception of mental imagery construed as private mental entities; that is, a kind of private, internal representational picture accessible only to the individual subject. One might derive Wittgenstein's argument indirectly from his infamous private language argument (PI §§256-258) and perhaps quite vividly from his beetle-in-a-box thought experiment (PI §293) but it is in $\$ 367$ where we can find a clear expression of his claim about mental imagery: "A mental image is the image which is described when someone describes what he imagines." Here Wittgenstein suggests an inextricable link between the mental image and various forms of descriptive responses the image would produce in the subject. ${ }^{1}$ This claim though is counterintuitive. The intuition here is that the mental image and the descriptive response to it are distinct, separate mental items that are somehow only contingently correlated. That is, one's linguistic or behavioral response plays only a contingent ancillary role to the image one has in mind. One can for instance apprehend the mental image without offering any response. Moreover, by emphasizing the descriptive response to the mental image rather than focusing on the apprehension of the very image itself, one may also suggest that Wittgenstein seems to be denying the existence of the private sensation - the qualia - involved in the apprehension of the image. While this has led many to attribute behaviorist inclinations in Wittgenstein's thinking about the mind, this is far from Wittgenstein's point about mental imagery. Wittgenstein is not denying the existence of an internal image. What he rejects is thinking of this internal image as a kind of picture the features of which simply depict or represent the bare perceptual properties belonging to an object.

Wittgenstein rejects here the common tendency to compare the properties of a private sensation with that of a visual display or representation such as that of an actual, physical photograph. This is made explicit in the second part of the PI, Philosophy of PsychologyA Fragment (hereafter PPF): "The concept of an 'inner picture' is misleading, since the model for this concept is the "outer picture" (PPF §133). Wittgenstein suggests that the image portrayed in the mind is fundamentally different in kind from the image, say, that obtains in a photograph. ${ }^{2}$ A mental image is not a private mental photograph. Photographs are fixed and static in the sense that the properties of the object remain unchanged through repeated viewings. A mental image on the other hand exhibits a dynamic quality that

\footnotetext{
${ }^{1}$ Wittgenstein has a very liberal notion of what constitutes a description. More than merely linguistic, a description for Wittgenstein can also be pictorial or gestural in form. Indeed, his very notion of language is just as liberal and capacious. See for example a remark in the Philosophical Grammar: "Think of the multifariousness of what we call 'language'. Word-language, picture-language, gesture-language, sound-language.” (PG p. 179)

${ }^{2}$ See Bennett and Hacker (2003) for a similar Wittgensteinian criticism of tendencies in neuroscience which take mental imagery as reducible to certain neural correlates or brain activity that supposedly pick out the private, "inner" qualia within the nervous system. To wit: "There is no such thing as looking at scrutinizing or viewing a mental image, hence too, no such thing as scanning one" (Bennett \& Hacker, 2003, p. 187).
} 
crucially depends on what we say and do with them (PI §377). That is, the dynamic quality produced in what we see is anchored on the forms of responses it induces in the subject. Viewing artworks are paradigmatic of this dynamic quality. A piece of painting, say, will look different to an untrained eye compared with an artist or an art critic, and these differences are revealed in precisely the way in which they would tend to respond upon viewing the painting. The artist or art critic can thus apprehend and recognize certain features in the artwork that an untrained eye would not in no small part because the latter simply lacks the requisite training in and initiation into these artistic circles.

To take a funnier illustration, an internet meme surfaced a few years back that placed Descartes' portrait alongside the Hollywood action star Sylvester Stallone. The uncanny resemblance between the facial features of the two figures gave the visual impression linking, somewhat strangely if not amusingly, one of the most ingenious thinkers of Early Modernity with the star of Rambo and Rocky as if they are one and the same person. Where before the connection may have never crossed one's mind, now the connection between Descartes and Stallone cannot be-to use an internet-friendly word- "unseen" because of the meme. Wittgenstein himself did speak of this very phenomenon: "I observe a face, and then suddenly notice its likeness to another. I see that it has not changed; and yet I see it differently. I call this experience "noticing an aspect"” (PPF §113).

Wittgenstein's point here is made in the context of his discussion of "seeing-as" where his famous duck-rabbit example comes up. When we notice a different aspect of an object we have never thought of before, such as recognizing Stallone in Descartes or rabbit ears in a duck's beak, Wittgenstein takes this alteration as operating at a fundamental perceptual level: "what is different: my impression? my attitude? - Can I say? I describe the change like a perception; just as if the object had changed before my eyes" (PPF §129). But as Wittgenstein contends, the perception isn't merely informed by the mere properties of the object but by its seeming relation with other things: "what I perceive in the lighting up of an aspect is not a property of the object, but an internal relation between it and other objects" (PPF §247). This is the dynamic quality with which mental images fundamentally differ from mere pictures or photographs. This dynamic quality in mental imagery cannot be accounted for by a mere recreation or representation of the object in one's mind. As Wittgenstein points out, a photograph qua object is just a piece of paper with a variety of pigments spread across its surface, but the image it produces in the mind is altogether different (PPF §252). What we perceive in the photograph goes beyond merely apprehending its physical properties as a flat rectangular surface with an assortment of pigments spread across it. No matter how much René Magritte in his famous La Trahison des Images (The Treachery of Images) exhorts us to think that the image he painted is not a pipe, we just can't help but see the pipe in the artwork, or when some random pattern on a piece of toast resembles the face of Jesus, it is hard to dissuade our visual sense from thinking that it is just simply an innocuous, random pattern of burn marks on bread.

So the image produced in the mind portrays not merely the brute visual inputs but more crucially its seeming connections with objects and concepts previously encountered. This 
dynamism is more apparent when one recognizes how malleable the seeming connections a mental image can prompt and induce, as clearly demonstrated in the duck-rabbit. In another remark, Wittgenstein elaborates on this dynamism in the context of a picture puzzle:

I suddenly see the solution of a puzzle-picture. Where there were previously branches, now there is a human figure. My visual impression has changed, and now I recognize that it has not only shape and colour, but also a quite particular 'organization'... If I represent it by means of an exact copy—and isn't that a good representation of it? — no change shows up.

And above all do not say "Surely, my visual impression isn't the drawing; it is this — which I can't show to anyone." Of course it is not the drawing; but neither is it something of the same category, which I carry within myself. (PPF §§131-132)

Wittgenstein here claims that mental images convey a kind of "organization" which accounts for one's shifting impressions of objects. This organization fundamentally differentiates mental images from actual picture objects which do not intrinsically possess this organizing structure. So it is not simply that a mental image of a duck-rabbit is such because it portrays or represents in a straightforwardly veridical way the same image illustrated on paper; there also seems to be some mental capacity involved that organizes the visual inputs in a way that conveys some emergent pattern or impression for the subject's apprehension.

\section{The Role of Conceptual Capacities in Determining the Content of the Mental Image}

So the question now comes down to identifying what this capacity consists in. Recognizing contrasting aspects in a single image shows us that having visual impressions is not a passive mental operation: a more active capacity is at play which "organizes" an object in view for one to see in one way or another. Two different individuals possessing similar perceptual equipment and receiving the same visual input can have different visual impressions because of the different ways they may have in organizing the visual input. One temptation here is to suggest a demarcation between the level of basic visual data where one accounts for the data from a more "objective" observational standpoint (such as identifying visual properties of objects like their basic shape or color) and then add another level where more "subjective" interpretations occur such as seeing a duck or a rabbit or some other figure in the same image.

However, even in these supposedly more basic observational statements regarding visual stimuli such as recognizing shapes and colors, Wittgenstein would still insist that an active element is still in play: "How do I know that this colour is red?-It would be an answer to say: 'I have learnt English”” (PI §381). That is to say, only in virtue of acquiring certain concepts about colors or shapes can it make sense for us to talk about even these basic visual impressions and accordingly respond in an appropriate manner if asked about them in relation to the relevant visual stimulus. It is not that the languageless individual (i.e. the prelinguistic child) is "blind" to these features; her perceptual equipment can receive the visual input but it is in her recognizing the content of the input as a particular color or shape 
which affects how she is able to respond and indeed perceive the stimulus. It is this recognition of content and the associated response it produces that the prelinguistic child needs to develop. Even in these basic perceptual observations of objects, some capacity to identify, individuate, and distinguish in an intelligibly responsive manner (as opposed to a mere stimulus-induced reaction) is already implicated which the child has yet to learn. In another way of saying, perception acquires intelligible, expressive content by virtue of the set of concepts one acquires. This is where Wittgenstein's Kantian inheritance is most apparent. John McDowell, in bringing together insights from Wittgenstein and Kant, describes how this conceptuality is instantiated at various levels in our encounter of the world:

Once we have equipped ourselves with this picture of how empirical substance is infused into concepts at the ground level, the level of observational concepts, it will seem straightforward to extend the picture from there. The idea is that empirical substance is transmitted from the ground level to empirical concepts that are further removed from immediate experience, with the transmission running along channels constituted by the inferential linkages that hold a system of concepts together. (McDowell, 1996, p. 7)

From this view, one cannot really speak of a strict delineation between apparently objective perceptual observations and supposedly subjective interpretations of those observations. Instead, we come to acquire a system of concepts which hold together both our basic perceptual observations and our more high-grade descriptions. So it may be better to think of the difference between recognizing basic shapes and colors and recognizing more complex features or properties of objects not in terms of kind but in grades or degrees of conceptual complexity, where one's perceptual responsiveness can gradually proceed from recognizing and identifying simple features such as colors and shapes to apprehending and appreciating more sophisticated features such as the fine artistic intricacies of, say, the smile of the Mona Lisa. In another sense, we do not apprehend the wider world around us in terms of shapes and colors alone so it would not be prudent to account for our visual impressions merely on these terms. We also have to account for these more "higher-grade" impressions that affect not just our perception but also the way in which we encounter and act in the world in general.

Moreover, more than possessing the relevant set of concepts that enables certain forms of responsiveness, what is critical for Wittgenstein is the way in which these mental images play a role in the context of our shared practices. That is, it is not so much the very representation of the image itself but in how that very representation plays a role in the "weave of human life" that makes the mental image what it is. The manifestation thus of an "inner" visual impression in one's mind reflects not an outright representation of the external object (which is not to say that this is not what we often think we do) but more like an expression of the ways in which we talk about or use the object in particular shared contexts. This fact about being able to talk about the expressive content of the mental image makes it possible for others to take the same object in the same light as how one sees it. Mental images construed as such are hardly private mental pictures, they convey aspects of an object that derive from our expressive practices arising from shared linguistic contexts. In that way the very expression of the mental image shows how the mental image 
can be made available to others (or oneself) through the proper teaching and justification of the words used in the expression, "[f]or if I need a justification for using a word, it must also be one for someone else" (PI §378).

\section{Two Notions of Experience and Mastering a Technique}

Wittgenstein doesn't just rely on talk of shared practices and language in accounting for mental imagery. In a critical remark he also claims: "Only of someone capable of making certain applications of the figure with facility would one say that he saw it now this way, now that way. [...] The substratum of this experience is the mastery of a technique" (PPF $\S 222$ ). This is in line with the earlier point made about some form of active capacity at play in mental imagery. However, to say that having a mental image involves mastering some form of technique seems to imply much more than a mere mental capacity. A technique suggests a kind of active intelligence involving some deliberate and conscious acquisition and learning of a skill (I will return to this point later). Wittgenstein immediately recognizes worries this would arouse: "how odd for this to be the logical condition of someone's having such-and-such an experience! After all, you don't say that one 'has toothache' only if one is capable of doing such-and-such" (PPF §223). Wittgenstein's worry here is that experience, like that of a toothache, is direct and immediate and is not mediated by techniques, descriptions, shared practices, and the like. But Wittgenstein tries to ease this concern by quickly saying that he's talking about a different and modified "though related" idea of experience (PPF §223). This quick reply, while suggestive, may strike one as unsatisfying, which is a quite common quibble in reading Wittgenstein's remarks. Perhaps a bit of exploration of this modified idea of experience can help us further cash out what Wittgenstein means.

Now having a mental image, let alone experiencing a toothache, may at first seem to take the form of a merely passive, receptive disposition. A perceptual impression is direct and immediate and thus does not strike one as requiring any form of acquisition or mastery of some skill. There is however an underlying assumption here that what determines the mental image or impression is some receptive perceptual faculty and that one's responses are merely contingent causal reactions to what is perceived. Wittgenstein would reject such an assumption. Marie McGinn tells us that Wittgenstein's remarks on aspect perception exhort us to think less of the relevance of the perceptual faculty and more towards the importance of the responsive agent in the determination of a visual impression. She writes:

The complexity in how our concept of visual experience functions... on the one hand, works against the temptation to rely on introspection to reveal the essence of visual experience, or to think of visual experience in terms of a subject's passive reception of what is given to sensory consciousness. On the other hand, it also works to underline the grammatical connections that exist between our use of the concepts of seeing and seeing-as and forms of behaviour - including gestures, verbal descriptions, abilities to draw or mimic, and so onin which the experiences of seeing and seeing-as are expressed. (McGinn, pp. 324-325) 
A similar theme of downplaying the role of a sub-personal perceptual faculty and emphasizing skillful, responsive engagement can be found in John Dewey. Dewey highlights the priority of movement and action, the "sensori-motor coordination," as opposed to merely focusing on the sensory stimulus, in "determining the quality of what is experienced" (Dewey, 1896, p. 358).

In other words, the real beginning is with the act of seeing; it is looking, and not a sensation of light. The sensory quale gives the value of the act, just as the movement furnishes its mechanism and control, but both sensation and movement lie inside, not outside the act. (Dewey, 1896, p. 359)

Relatedly, Wittgenstein in another remark also claims that a perceptual impression is also infused with an element of thought:

Someone who looks at an object need not think of it; but whoever has the visual experience expressed by the exclamation is also thinking of what he sees. [...] And that's why the lighting up of an aspect seems half visual experience, half thought. (PPF §139-140)

Mere looking in terms of using one's visual perceptual faculty is something we ostensibly share with other animals. But it is not clear that these other animals can also have an associated thought or content in mind connected with the perceptual input. Wittgenstein seems to imply that having a visual impression is different from merely having to pick up on perceptual cues. Rather than being brute perceptions of external objects, the contents of our visual impressions are obtained from concepts we acquire which then enable us to make sense of what is seen in an intelligibly responsive and publicly expressive manner. For Wittgenstein, the mere fact that we are able to convey our visual impressions in a responsive and intelligible way suggests that these experiences possess a constitutive (and not merely added) element of thought and conceptuality.

The key insight in this modified notion of experience is that a perceptual impression is not just determined by a subject's receptivity to perceptual input (which is trivially true in terms of its necessary causal role in experiencing the perceptual impression), but more importantly, the impression or quality of what is seen is shaped by the forms of shared expressive content and responsive engagement it makes possible. That is, the perceptual impression arises from how the subject engages with the world manifested in the way the subject talks about, acts on, depicts, and shares his impressions with others insofar as the impression contains mutually shared and understood expressive content. Moreover, for McDowell, one can only make sense of the content of experience insofar as "conceptual capacities" are in place which can be "exploited in active and potentially self-critical thinking" (1996, p. 66). It is essential here that in possessing concepts, McDowell is also pointing us to the fact that these concepts are capacities that enable the perception to possess expressive content that can be consciously reflected on. It is not as if we perceive things in the world first in a sort of pre-conceptual manner and after which we map it onto some conceptual space or interpretative framework constructed by the understanding (though we may do this sort of thing too at another, less fundamental level). Instead, our very 
experience of things in the world is itself already infused with and informed by the understanding in which conceptual capacities are at work. Visual impressions thus bear content only insofar as they possess some form of expressive conceptual character. Perceptual sensory content as a pre-conceptual "given" that impinges upon our conceptual frameworks is, as Wilfrid Sellars (1956/1963) calls it, a myth.

Still, talk of active thinking subjects and conceptual capacities may not be enough. After all, helpless, guileless newborns can ostensibly see and form images of the world around them without the help of acquired concepts. Upon birth they do not yet possess language but they already carry with them working perceptual equipment which enables them to perceive and form images of their surrounding environment. The retort here could be that the life of the newborn child is qualitatively different from the life of the mature, languagewielding adult. It is likely that two very different notions of experience are at play here. There is experience qua mere receptivity to perceptual input where the inborn perceptual equipment is enough to account for the brute perception of one's immediate environment. But we can also talk about the richer, more interesting type of experience qua dynamic, content-bearing impression that is available for reflective, expressive, and responsive thought. This latter sense of experience requires more than the use of one's inborn perceptual equipment. So if the mere perceptual equipment is not sufficient, we need to add something else to account for this richer sense of experience. If Wittgenstein is right, it all comes down to acquiring the right kind of technique, in particular the acquisition of certain conceptual capacities. So in acquiring conceptual capacities, one undergoes a qualitative change in how one perceives visual impressions, from mere receptivity to perceptual input that is limited to environmentally adaptive, stimulus-response type of reactions, to the more dynamic content-bearing and responsive perceptual impressions human beings can have.

\section{Visual Affordances}

Another useful way to cash out the relevance of conceptual capacities in visual impressions is through the notion of an affordance (Gibson, 1979/1986). An affordance connects a creature with its surroundings in terms of the forms of action (and thought) the environment makes possible in relation to the dispositions, faculties, or skills available to that creature. So a disposition, faculty, or skill can in a manner of speaking "afford" certain actions on the basis of available features and objects in the surrounding environment. For example, a chair affords sitting on, a flat ground affords walking on, a pen affords writing and so on. These actions are only possible when we are in a setting or context where these environmental features or objects are salient. Think now of the rich variety of actions made available to us humans based on the objects and environments (both natural and constructed) we surround ourselves with: the available environment offers contextual signals which predispose or attune us to engage in certain forms of skillful activity. 
So what is the relevance of affordances to mental imagery? We can talk about visual affordances; that is, things that "show up" given certain contexts and environmental conditions. But these visual affordances will only show up given the relevant faculty or skill available to the subject. A basic perceptual faculty such as that already available in the newborn enables her to afford brute perceptual affordances. But the human visual faculty is capable of seeing much more than brute perceptions such as, say, acquiring an aesthetic sensibility. We also talk about acquiring an "expert eye" where training in a particular practice opens us up to specialized visual affordances. For example, neuroscientists can explain in detail what is going on in one's brain by looking at PET scans. Someone trained in electronic circuitry can understand the lines and symbols drawn on a circuit schematic diagram (cf. PG, p. 176). Specific bodily cues and gestures can open up a whole language when one learns to sign. Acquiring certain skills thus enables possibilities for sight, in particular, noticing relevant aspects in the environment. In a similar vein, Alva Noë talks about the relevance of skill acquisition in achieving access to certain features in the world:

We achieve access to the world. We enact it by enabling it to show up for us. Sometimes we fail. There are different ways we can fail to achieve access to the world; there are different ways the world can fail to show up for us. If the skills needed to pick up a feature are absent, then the feature is not present in our experience. If I don't have the relevant skills of literacy, for example, the words written on the wall do not show up for me. I can't see them, even though they are there. I lack the skills. This is just the way the words can fail to show up for infant children, or for my dog. (Noë, 2012, p. 191)

Insofar as concepts give way to thought, conceptual capacities may at first seem to open up possibilities for thinking, not visualizing. Consider however the point noted earlier about Wittgenstein's liberal notion of descriptions and language. A language for Wittgenstein is not merely limited to words, utterances, and propositions. Some languages can be pictorial or gestural in nature. Indeed, meaning can be conveyed by any combination of these elements. The same thing can said about conceptual capacities. Concepts can take the form of words, utterances, propositions, gestures, pictures or any combination of these which can be used to convey expressive content. Conceptual capacities construed as such are hardly mental operations that are mapped onto perceptual input. These capacities themselves make possible the very world one inhabits, in which one's perception is itself informed by its very expression. In this sense, conceptual capacities are deeply embedded in the world around us and in how one sees it. We cannot convey these concepts without making some intentional connection with some accessible feature or object in the world. As Noë notes, "[t]o learn a concept is to learn to grasp something to the world around us" (2012, p. 127). The concept of "redness," only makes sense because of its intentional relation with certain features or objects in the world associated with the impression it conjures. The same ostensibly applies for other higher-order concepts. Conceptual capacities as such enable a wide latitude of affordances. Not only do they open up particular sets of actions or thoughts, but, more fundamentally, they also make possible a particular way of seeing and encountering the world. 
It should be noted here that the role of affordances in apprehending a mental image banks on the possibilities for responsiveness the image induces. The McGinn passage quoted above reveals how Wittgenstein's grammatical investigation into our visual impressions suggests an intimate link between the very impression and how we respond to the impression. These possibilities for responsiveness can come in various forms, be they linguistic or gestural/behavioral or in the form of a drawing or illustration or perhaps a reenactment or imitation and so on (as noted, these are for Wittgenstein different forms of descriptive responses). What these various forms of responding have in common are the ways in which these responses convey how the mental image is apprehended. A given mental image thus affords certain responses depending on the relevant conceptual capacity possessed by the subject. The responsiveness arises because the mental image contains meaningful, expressive content which the subject recognizes and gives some form of response in virtue of that recognition. Recognizing the image of Jesus on toast affords a very different response from merely seeing burn marks. Acquiring certain conceptual capacities as such enables certain possibilities for sight in terms of noticing relevant aspects in the environment to which one responds to in a way that betrays the expressive conceptual content of what is seen.

A relevant question is how we ought to think about affordances in light of the various forms of responses a mental image makes possible. Rietveld and Kiverstein (2014) offer us a richer understanding of affordances by linking it with the Wittgensteinian notion of forms of life. Humans in particular exhibit a wide variety of forms of life. The skills and practices of a Filipino farmer working in a rice field differ significantly from the skills and practices that afford one to be a successful corporate lawyer working in one of the high rises of Manhattan. Embedding affordances within forms of life allows us to talk about possibilities for thought and action that are meaningful and significant within a shared practice. We are not just talking about generic actions like walking, sitting, or eating. We are also talking about actions that require some sensitivity to certain norms of a shared practice or social-cultural context such as conversing, writing, teaching, praying, designing, building and so on. These are actions that carry special significance for us humans and they only make sense within the larger context of a form of life. Insofar as acquired conceptual capacities help activate these significant forms of action, it can be said that these capacities can also enable meaningful visual affordances. The visual world that opens up for us is a world of significations that further afford meaningful actions and responses. If a perceptual faculty predisposes the possessor to open up merely brute perceptual affordances available in the environment suitable for adaptation, conceptual capacities can open our eyes to a vast array of meaningful affordances - they enable possibilities for thoughtful and meaningful visual impressions given the right context. At times, these meaningful visual affordances can even be found in unexpected places, again like recognizing the image of Jesus on a piece of toast which is only likely to appear to a person immersed in or at least familiar with a Christian form of life. Thus, beyond brute perceptual affordances, human beings qua language users and cultural participants can afford visual impressions with rich practice-based significations. This is how conceptual capacities does its work in informing visual input to convey meaningful visual impressions. 
While thus far I have been advocating the usefulness of the notion of acquired conceptual capacities, it also raises some concerns unique to it. Explaining inborn perceptual equipment for example seems pretty straightforward. One can account for it by looking at its relevant biological composition, its functional role, adaptive evolutionary mechanisms that shaped it and so on. When it comes to conceptual capacities, it is not as straightforward. What is the nature of these capacities? How do we acquire them? And how is it that they can affect at a fundamental experiential level our encounter with the world? I do not aim to answer these questions in this paper but what I want to offer in the next section is a more robust account of how these conceptual capacities work to produce the wide range of mental imagery we can possess. At this point of our inquiry Wittgenstein may not be as useful. Wittgenstein's remarks can seem at once illuminating and insightful but at the same time frustratingly cryptic and short on explanatory detail. In the following section I move beyond Wittgenstein's merely suggestive remarks and attempt to cash out a more robust account of conceptual capacities using Gilbert Ryle's notion of dispositions.

\section{Acquired Conceptual Capacities as Responsive Dispositions}

Ryle, in his discussion of dispositions, picks out those dispositions that are intrinsic to the object or creature and those that are acquired (Ryle, 1949/2009, p. 30). An example of an intrinsic disposition is the disposition of glass to break when smashed or of a perceptual faculty to receive visual data. One can pick out acquired dispositions on the other hand in one's habits, mannerisms, and various learned techniques and skills. Within the set of acquired dispositions however Ryle makes a further distinction between those that are merely habitual or routine from those that require constant improvement and mastery through deliberate practice, what he calls "intelligent capacities" (p. 30). Examples of the latter include skills acquired in engaging in athletic or artistic or intellectual pursuits, all of which require constant practice. Habits on the other hand, while also acquired and learned, are automatic and hardly require conscious effort and attention once acquired (p. 42). Examples of such "blind" habits are rote behaviors such as walking, eating, reciting the pledge of allegiance and so on.

However, some of the intelligent capacities mentioned above can at times, especially when well-mastered, be executed as a matter of "blind" habit. Also, some of the habits mentioned may require deliberate and attentive effort (such as when one tries to walk across a creaky suspended bridge). Perhaps these different forms of acquired abilities or "second natures" as Ryle calls them may differ not in kind but in degree. Still, it may be useful to distinguish capacities that are constantly performative, that is, requiring constant improvement, fine-tuning, and regulation, from those capacities that are merely habitual or routine. Note Ryle's description of intelligent capacities or skills:

Knowing how... is a disposition, but not a single-track disposition like a reflex or a habit. Its exercises are observances of rules or canons or the applications of criteria, but they are not tandem operations of theoretically avowing maxims and then putting them into practice. 
Further, its exercises can be overt or covert, deeds performed or deeds imagined, words spoken aloud or words heard in one's head, pictures painted on canvas or pictures in the mind's eye. (Ryle, 1949/2009, p. 34)

I reckon that the critical difference between intelligent capacities and habits is the former are considered substantially normative, requiring constant feedback and practice, while the latter are hardly normatively guided (not to say that they are not grounded on norms but that they employ norms in a very minimal, almost inconsequential sense). Mastering a habit, say walking, does not require much normative maintenance after one has mastered it. An intelligent capacity on the other hand, despite acquiring or even mastering it, still needs that constant feedback and normative guidance; that is, the person should be "ready to detect and correct lapses, to repeat and improve upon successes, to profit from examples of others and so forth. He applies criteria in performing critically, that is, in trying to get things right" (Ryle, 1949/2009, pp. 17).

As noted earlier, visual affordances have degrees of complexity: from having an impression of mere shapes and colors to having an expert eye. I suggest following this the degree of complexity of a certain conceptual capacity tracks the degree of dispositional sophistication required to afford the corresponding visual impression. It should not take a lot to master the concept of "redness." Simple concepts like colors afford "single-track" visual impressions. Once one acquires the concept its application is merely repetitive and habitual. There is really nothing more in acquiring the concept of "redness" that requires one to improve on one's application of the concept. Either you recognize a red pigment or you do not. On the other hand, knowing the difference between an original piece of art and a mere replica is not as straightforward. The application of this sophisticated eye for spotting the minutest of differences requires more deliberate skill and the application of the skill is not just a matter of routine. Each case affords its own set of challenges which demands critical normative use of a set of skills possessed by an expert. Acquired conceptual capacities as such can be instantiated in a wide latitude of acquired dispositions from mere "blind" visual habits to more normatively-guided and deliberately-trained visual abilities. This shows the wide and dynamic range of visual impressions that can be made available for human beings.

One might object that using Ryle to expound on conceptual capacities might give ideas that this account is veering uncomfortably close towards philosophical behaviorism. First of all, whether Ryle is actually a behaviorist in the way that behaviorism is characterized (and easily dismissed) today in philosophy of mind is a matter of dispute. ${ }^{3}$ Second, nowhere in the discussion of mental imagery thus far suggests anything endorsing behaviorism. There is of course the suggestion linking mental imagery with its descriptive response and expressive content but this amounts to a re-characterization of the notion of firstpersonal access to experience rather than an outright denial of it. The critical move here is the articulation of the role of conceptual capacities in an account of the determination of

\footnotetext{
${ }^{3}$ See for example Julia Tanney's introduction to Ryle's The Concept of Mind (Ryle, 1949/2009).
} 
mental imagery from the perspective of the subject's skillful, active, and responsive engagement rather than a focus on the role of a merely receptive perceptual faculty.

The determination of the mental image from one's skillful, active, and responsive engagement may again seem counterintuitive when one grasps certain features such as colors or shapes or even expressions on a face, as is usually invoked by Wittgenstein. It seems that at least for certain images and impressions, the grasping is direct, immediate, and unmediated. I suggested above that this grasping already involves conceptual capacities which determine the content of the image or impression. The application of conceptual capacities need not be done in a conscious, deliberate, and reflective fashion. This conceptual understanding can be applied, to use Wittgenstein's phrase, "at a stroke," that is, in an intuitive and immediate sense and in a way that appears as if one is merely being receptive to the content of the impression. This can happen for visual habits as well as at times for normatively-guided and intelligent perceptual capacities. Indeed it is often a mark of expertise that one's deliberately-trained skill can be deployed in an almost automatic and intuitive manner.

Again, it is important to note here that talk of conceptual capacities is not limited to grasping propositional or verbal content. The intelligible conceptual content of the mental image can also take the form of a gestural or embodied or pictorial mode of understanding. An imitation or re-enactment or an artwork can be considered non-propositional modes of conveying the intelligible content of what is perceived. Kristóf Nyíri has argued against a received reading of Wittgenstein that stresses the primacy of verbal language in human understanding. Instead, he argues that the visual and motor dimensions of cognition play a primary and fundamental role in that understanding:

Verbal language emerges from the natural language of facial expressions and gestures, which are movement and image at the same time... The human mind is primarily visual and motor. It is not through the mediation of words we make contact with reality, but through direct perception, with visual perception playing the definitive role. (Nyíri, 2017, p. 50)

This I think is an important insight and there might be something worth exploring here especially from a developmental perspective. My sense however is that the visual and motor dimensions do play a huge role in the ontogenetic development of the human mind but once developed, words and utterances would not so much take over so much as incorporate themselves into the relevant mental processes. That is, the verbal, visual, and motor dimensions eventually get integrated in human cognition in such a seamless manner that it may not make sense to ask which is primary in a mature mind. In the beginning was indeed the deed (CV p. 31), but our concern here is the mature and developed form of the human mind. Visual, embodied, and other modes of sensori-motor understanding do still play their part but spoken and written language are just as important. ${ }^{4}$ (Consider for example how novels can have an impact on us in almost the same way as films). Nevertheless, conceptual capacities, in whatever shape or form they take, determine the very content of

\footnotetext{
${ }^{4}$ I thank an anonymous referee for directing me to Nyíri’s work.
} 
the mental image. One may respond to the image by imitating, verbally describing, drawing, or pointing at a similar picture - all of which can be deemed legitimate forms of intelligently responding to the recognized content of the image.

One of the important takeaways here is that our visual sense contains a kind of intelligence, one which can be trained to see things that would not appear or be accessible without the prior training. What sort of visual affordance is activated is determined by one's initiation into a shared practice. Different practices afford their own distinctive way of seeing which would not be accessible outside the context of the practice. A person with no training or immersion in abstract art will have a difficult time appreciating it. Abstract artists and art critics, in creating or viewing abstract art, can describe abstract artworks in very articulate and meaningful detail whereas the untrained person would just be reduced to dictating the shapes and colors she sees (cf. PPF §168). The artists and art critics as such exhibit a kind of visual intelligence in creating or viewing abstract art.

This last example vividly shows how our perceptual impressions can come to have a normative dimension. There are norms that guide how a piece of art can be created or described in a way that is normatively appropriate in the abstract art world. A descriptive response that merely enumerates the shapes and colors one sees in the artwork will just not make the cut. How then does one determine what is a normatively appropriate descriptive response? For one, the normative adequacy of the response does not depend on some inner subjective interpretation but on the norms that guide the very practice from which the image derives its expressive content. In other words, the expressive content of the impression is determined and at the same time normatively-guided by the relevant shared practice or language-game in play. As McGinn expounds on Wittgenstein:

Whether a description that I give of my visual experience is incomplete depends upon whether the person I am giving the description to understands what I want to convey. A drawing of the figure 'may be an incomplete description - if some question still remains' (PPF §156). [...] What Wittgenstein wants us to see is that there is an indefinite number of descriptions of what is seen... each one serving a different purpose, and none of which qualifies as the 'one genuine, proper case of such description - the rest just being unclear, awaiting clarification, or simply to be swept aside as rubbish' (PPF §160). (McGinn 1997/2013, p. 323-324)

Mental images as such have a normative profile not based on how it accurately or reliably represents an object in the world but on the manner in which the relevant conceptual capacity is used in the appropriate shared context in conveying what is seen. Moreover, the descriptive responses conveyed can be understood as something like "instruments for particular uses” (PI §291) the proper deployment of which depends on whether they serve as sufficient responses situated within the relevant shared context. In other words, whether the act of conveying is sufficient or complete depends on whether the relevant conceptual capacities are used in a manner that accords with the proper norms of the language-game in play. 


\section{Conclusion: The Expressive Plurivocity of Mental Imagery}

The preceding discussion of mental imagery makes clear that there is no univocal manner of expressing the content of a mental image. Instead we should recognize the dynamic and reflexive plurivocity that perceptual impressions have the potential to convey. There is no single expression that will capture the essence of what is perceived. Each expression conveys its own distinctive meaning which can only be understood and appreciated within the context of a particular shared practice. Of course, mental imagery depends on the input of visual data but the sensory data alone does not determine the impression. The visual data received by the perceptual faculty plays a necessary causal role in the determination of the mental image, but it is not sufficient. As language users, we also possess the means to give expressive content to what we see. It is in this ability to express the content of what we see where we find diversity. But it is not an anything goes diversity: the visual input serves to anchor the impression in a way that limits the normative range of acceptable expressions. The sight of a soccer ball should give the impression of a round, spherical object, and not any other shape. But there is no concept that serves as the foundation or essence on which all expressions must be based on. A soccer ball is more than just a round, spherical object. The range of possible responses the ball elicits conveys its meaning within the particular community of soccer athletes and enthusiasts. The expressive content of mental imagery as such are only intelligible within these specific contexts or forms of life. An extra-contextual foundation on which to base the correctness of an expression of what is seen is for Wittgenstein an illusion.

In acquiring a conceptual capacity one enters a world of significations. Rather than having a purely representational function, conceptual capacities have a more fundamental revelatory function in unraveling the world before the subject. It enables subjects- to use McDowell's words - to "have the world in view." In this more fundamental sense, conceptual capacities are not in the business of merely processing perceptual input. Its transcendental significance owes to the fact that it opens up a world to the individual as opposed to simply reacting and adapting to environmental stimuli. Unlike other animals whose experience ostensibly only amounts to a sensory sensitivity to features of the immediate environment sufficient for coping and survival, the world that is rendered for human beings is one that is thoroughly normatively structured and made intelligible in a way that opens it to reflective, responsive, and expressive thought. This is the fundamental sense of intelligence which conceptual capacities provide for humans. This intelligence does not offer a static or univocal means of expressing what is seen: what it makes possible is a dynamic and reflexive plurivocity in conveying visual impressions. There is no single expression of a mental image that will capture the essence of the image. Each expression conveys its own distinctive meaning which can only be understood and appreciated within the context of a shared practice.

I would like to conclude by briefly pointing out a few educational implications of this account of mental imagery. Insofar as our visual sense can exhibit a plurality of meaningful expressions, there is always an opportunity for learning: 
The acquisition of a skill by a novice involves what Gibson has called an "education of attention" (Gibson, 1979/1986, p. 254, as cited in Ingold, 2000/2011, p. 354). The process of educating attention crucially involves other practitioners who selectively introduce the novice to the right aspects of the environment and their affordances. [...] So in the process of education of attention the novice is brought to a selected aspect of the world that is of significance to the given practice and shown landmarks that orient his or her activities. In this way the novice learns what possibilities for action an aspect of the environment provides. (Rietveld \& Kiverstein, 2014, p. 331)

Thinking of our visual sense as having this kind of skillful, even creative, form of intelligence instead of having a merely brute perceptual function shows the many ways in which our perceptual impressions can be cultivated and expanded and diversified. It is not just about having true basic observational beliefs. Higher forms of understanding and engaging with the world are also deeply rooted in the perceptual domain. Perceptual impressions taken in this more capacious sense therefore indicate and reveal ways of seeing that can be truly transformational. Acquiring conceptual capacities is in this way akin to being initiated into a new way of seeing the world, which, to use Wittgensteinian imagery, is like a light gradually dawning over the whole.

\section{References}

Bennett, M. R., \& Hacker, P. M. S. (2003). Philosophical Foundations of Neuroscience. Oxford, UK: Blackwell.

Dewey, J. (1896). The Reflex Arc Concept in Psychology. Psychological Review, 3(4), 357-370.

Gibson, J. J. (1986). The Ecological Approach to Visual Perception. Hillsdale, NJ: Erlbaum. (Original work published 1976)

McDowell, J. (1996). Mind and World. Cambridge, MA: Harvard University Press.

McGinn, M. (2013). Wittgenstein and the Philosophical Investigations. London, UK: Routledge. (Original work published 1997)

Noë, A. (2012). Varieties of Presence. Cambridge, MA: Harvard University Press.

Nyíri, K. (2017). Pictorial Truth: Essays on Wittgenstein, Realism, and Conservatism. Dunabogdány, Hungary.

Rietveld, E., \& Kiverstein, J. (2014). A rich landscape of affordances. Ecological Psychology, 26(4), $325-352$.

Ryle, G. (2009). The Concept of Mind. Oxford, UK: Routledge. (Original work published 1949)

Sellars, W. (1963). Empiricism and the Philosophy of Mind. In W. Sellars, Science, Perception, and Reality. London, UK: Routledge. (Original work published 1956) 
Wittgenstein, L. (1963). Philosophical Investigations. (G. E. M. Anscombe, Trans.). Oxford, UK: Basil Blackwell. (PI)

Wittgenstein, L. (1967). Philosophical Grammar. (R. Rhees Ed., A. Kenny, Trans.). Oxford, UK: Blackwell. (PG)

Wittgenstein, L. (1980). Culture and Value. (G. H. von Wright in collaboration with H. Nyman Eds., P. Winch, Trans.). Oxford, UK: Blackwell. (CV)

The editorial and publishing process of this publication has been financed by the research grant "What is Thinking with Images?", SONATA 10, granted by the National Science Centre, Poland, on the basis of the decision No. 2015/19/D/HS1/02426. 